tibial bowing, severe talipes, hypoplastic scapulae, mental retardation, sex chromosome reversal in some affected females, and severe respiratory difficulties in infancy. One other differential diagnosis of kyphomelic dysplasia is the femoral hypoplasia-unusual facies syndrome which is sporadic $^{67}$ or rarely autosomal dominant ${ }^{8}$ and hence the diagnosis has important counselling differences. Cleft lip and palate has previously only been described in FH-UFS. It now seems that it cannot be used to differentiate the two syndromes, ${ }^{5}$ the major difference remaining symmetrical femoral bowing in kyphomelic dysplasia and femoral hypoplasia in the FH-UFS, which is often asymmetrical.

The prognosis appears to be encouraging, but as yet no adults have been described. Femoral angulation improves with age although adult stature is likely to remain short with some limitation of movement at the hips and knees. Cervical subluxation is the most serious complication reported ${ }^{3}$ and it must be actively sought. Osteoarthritic problems could be predicted in the future for our patient in view of the osteochondritic changes in the femoral epiphysis.

Apnoea has not previously been reported as a feature of the condition although frequent respiratory infections secondary to a small chest have been described and could be postulated as an underlying cause in our patient.
This case helps to delineate further the features and natural history in this rare skeletal dysplasia.

The authors would like to thank the family of the proband for their cooperation in preparing this report.

\section{References}

${ }^{1}$ Khajavi A, Lachman R, Rimoin D, et al. Heterogeneity in the campomelic syndromes. Long and short bone varieties. Pediatr Radiol 1976;120:641-7.

${ }^{2}$ Hall BD, Spranger JW. Familial congenital bowing with short bones. Pediatr Radiol 1979;132:611-4.

${ }^{3}$ Maclean RN, Prater WK, Lozzio CB. Brief clinical report. Skeletal dysplasia with short angulated femora (kyphomelic dysplasia). Am J Med Genet 1983;14:373-80.

4 Rezza E, Iannaccone G, Lendvai D. Familial congenital bowing with short thick bones and metaphyseal changes, a distinct entity. Pediatr Radiol 1984;14:323-7.

5 Viljoen D, Beighton P. Kyphomelic dysplasia: further delineation of the phenotype. Dysmorphol Clin Genet 1988;1:136-41.

6 Pitt D. Kyphomelic dysplasia versus femoral hypoplasiaunusual-facies syndrome. Am J Med Genet 1986;24:365-6.

${ }^{7}$ Maclean RN. Letter to the editor. Reply to Dr Pitt. Am J Med Genet 1986;24:367-8.

8 Burn J, Winter RM, Baraitser M, Hall CM, Fixen J. Femoral hypoplasia-unusual facies syndrome. J Med Genet 1984;21: 331-40.

Correspondence to Dr I Karen Temple, Department of Clinical Genetics, Institute of Child Health, 30 Guilford Street, London WC1N 1EH.

\title{
A case of two inversion (10) recombinants in a family
}

\author{
P ROBERTS*, J WILliaMS*, AND M A SILlS $\dagger$ \\ ${ }^{*}$ Department of Cytogenetics, St James's University Hospital, Leeds; and †Department of Paediatrics, \\ Huddersfield Royal Infirmary, Huddersfield.
}

SUMmARY A family is described in which the mother's four pregnancies resulted in one spontaneous abortion, one healthy boy, and a male and female sib with developmental delay and multiple minor dysmorphic features. Chromosome analysis showed a large pericentric inversion of chromosome 10 , involving the region between bands $\mathrm{p} 15.1$ and $\mathrm{q} 25.2$, in the father and the healthy son: $46, X Y$,inv(10) (p15.1q25.2), and an unbalanced karyotype in the two affected sibs: rec(10),dup p,inv(10) (p15·1q25.2).

The unbalanced chromosome has been produced by meiotic recombination between the

Received for publication 16 February 1989

Accepted for publication 17 February 1989. inversion chromosome and its normal homologue. The two affected sibs have partial duplication of $10 \mathrm{p}$ and partial deficiency of $10 \mathrm{q}$, and share a large number of clinical features, several of which have previously been described in both of these chromosome imbalances.

We believe this to be the largest pericentric inversion of chromosome 10 reported to have produced recombinant offspring.

\section{Case reports}

CASE 1

The male proband was the third child of healthy, unrelated parents, born at term by normal vaginal delivery after an uneventful pregnancy. His birth 


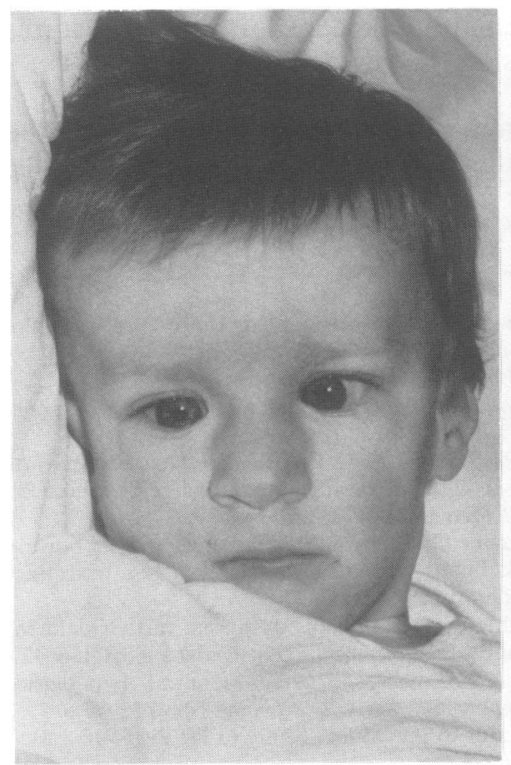

(a)

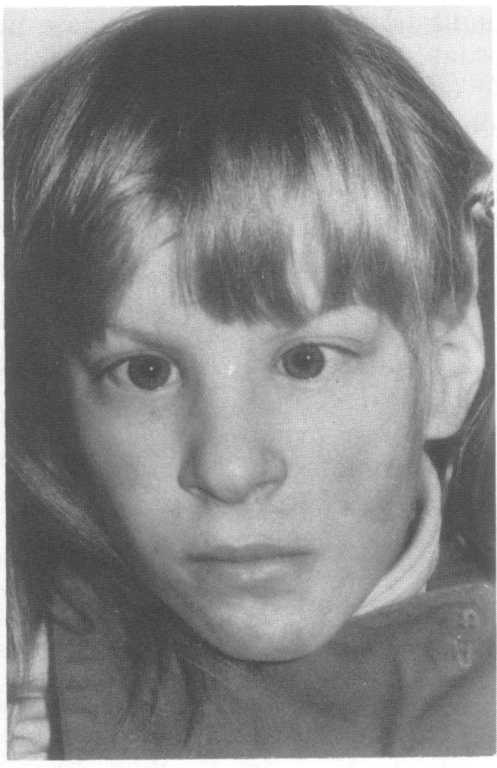

(b)
FIG 1 (a) Case 1 at 18 months. (b) Case 2 at nine years. weight was $3500 \mathrm{~g}$ (50th centile). He was noted to be floppy, had a weak cry, and had difficulty in establishing feeding. He subsequently showed mild to moderate developmental delay.

Examination at 14 months showed his height and weight to be on the 50th centile, while his head circumference was below the 3 rd centile. He had minor dysmorphic features consisting of low set ears, a convergent squint, and a long, prominent nose (fig 1a). He was also noted to have an umbilical hernia, bilateral cutaneous syndactyly of his second and third toes, and bilateral undescended testes.

\section{CASE 2}

His sister, the oldest of the sibship, was born by normal vaginal delivery at term after an uneventful pregnancy. Her birth weight was $3400 \mathrm{~g}$ (50th centile). She required resuscitation in the immediate neonatal period and subsequently also had feeding and respiratory difficulties in the first week. Transient thrombocytopenia of undetermined origin was also observed.

At the age of six months she developed fits, the EEG showing a left sided paroxysmal discharge. Phenytoin controlled her fits at the age of six without further recurrence. She has since exhibited moderate to severe developmental delay with significant behavioural problems and hyperactivity.

Physical examination at the age of eight months showed her weight and head circumference to be on the 3rd centile, while her height was below the 3rd centile. Her facies was similar to her sib's (fig 1b). Like her sib, she had an umbilical hernia and a mild degree of cutaneous syndactyly of her second and third toes bilaterally.

\section{CYTOGENETIC STUDIES}

Seventy-two hour lymphocyte cultures released from a methotrexate block with thymidine enriched medium $^{1}$ were set up for the three liveborn children and the parents, and used to make GTL banded chromosome preparations. The products of conception from the spontaneous abortion were not available for cytogenetic analysis.

A pericentric inversion of chromosome 10 was found in the father and the healthy son, $\operatorname{inv}(10)(p 15.1 q 25.2)$, and a recombinant of this inversion was found in the proband and his sister, rec(10), dup p,inv(10)(p15.1q25.2) (fig 2).

The mother's chromosome analysis was normal. The pedigree is shown in fig 3 .

\section{Discussion}

Duplication/deficiency as a result of meiotic behaviour of pericentric inversions of chromosome 10 has been reported on several previous occasions. ${ }^{2-5}$ Two recombinant sibs have been produced in this family and we believe that the large size of the inversion has resulted in an increased possibility for 
meiotic recombination. The viability of the two recombinants is explained by the fact that the amount of duplication/deficiency is relatively small. We believe this to be the largest pericentric inversion of chromosome 10 reported to have produced recombinant offspring.

Our two sibs with the recombinant chromosome 10 have partial duplication of $10 \mathrm{p}$ and partial deficiency of $10 \mathrm{q}$. It is difficult to discriminate clinically between the phenotypic features contri- buted by the two chromosomal imbalances. The main diagnostic features of partial duplication 10p were described by Lurie $e t a t^{t}$ as dolichocephaly, prominent forehead, wide open sutures and fontanelles, cleft lip and palate, broad root of the nose, club foot, and cystic changes of the kidney. Other features commonly associated include physical and mental retardation, dysplastic ears, heart defects, hypertelorism, and microgenia. Our two affected sibs display only a few of these (table), which

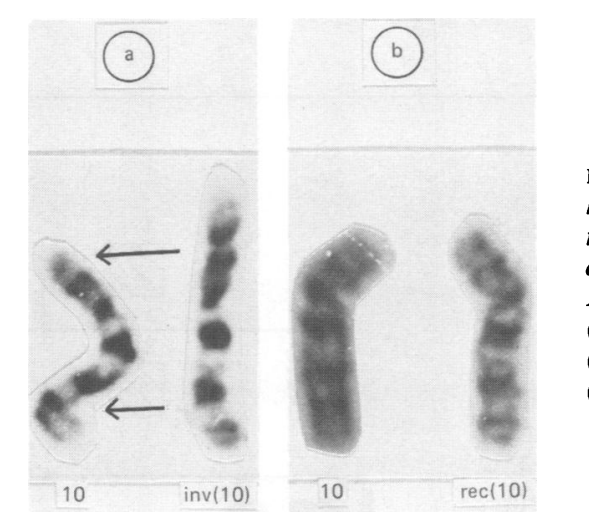

FIG 2 Partial GTL banded

karyotypes and schematic representation of the inversion and recombinant 10. (a) Father (inversion 10 on right). (b) Proband

(recombinant 10 on right). (c) Normal 10.

(d) Inversion event. (e) Inversion 10.

(f) recombinant 10 .

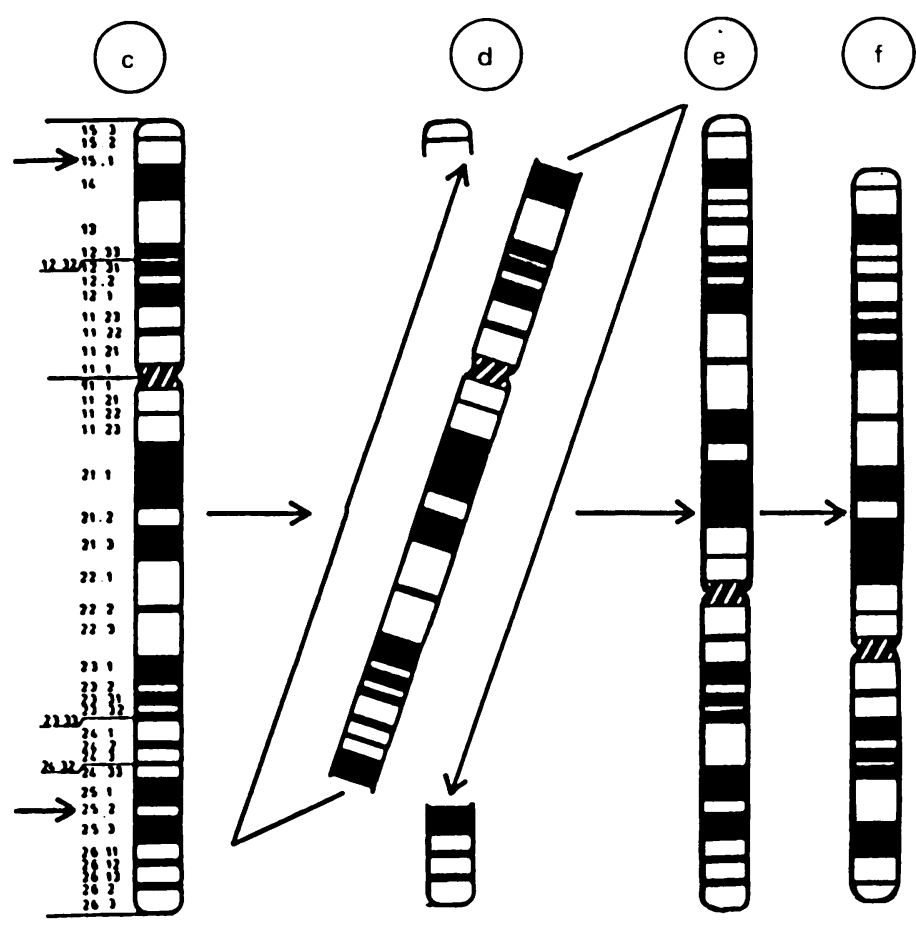


TABLE The main clinical features of cases 1 and 2 and their correspondence with the features documented by Lurie et al ${ }^{b}$ for partial duplication $10 p$ and by Shapiro et al and Mehta et al ${ }^{8}$ for partial deficiency $10 q$.

\begin{tabular}{|c|c|c|c|c|}
\hline Clinical findings & Case 1 & Case 2 & Duplication $10 p$ & Deficiency $10 q$ \\
\hline Neonatal feeding problems & + & + & - & - \\
\hline Neonatal respiratory problems & - & + & - & + \\
\hline Weak cry & + & - & - & - \\
\hline Hypotonia & + & - & - & + \\
\hline Low set ears & + & + & + & + \\
\hline Strabismus & + & + & - & + \\
\hline Long, prominent nose & + & + & + & + \\
\hline Physical/mental retardation & + & + & + & + \\
\hline Developmental delay & + & + & - & + \\
\hline Behavioural problems & - & + & - & + \\
\hline Fits & - & + & - & - \\
\hline Hyperactivity & - & + & - & + \\
\hline Undescended testes & + & - & + & + \\
\hline Cutaneous syndactyly & + & + & - & + \\
\hline Umbilical hernia & + & + & - & - \\
\hline Thrombocytopenia & - & + & - & - \\
\hline
\end{tabular}

concurs with the observation by Yunis and Torres de Caballero $^{2}$ that partial duplication $10 \mathrm{p}$ is not a clinically recognisable entity.

Shapiro et al described the main features associated with partial deficiency $10 \mathrm{q}$ as respiratory problems at birth, abnormal ears, prominent nasal bridge, hypertelorism, strabismus, and a short or webbed neck. Other common features include low birth weight, microcephaly, developmental delay, and growth retardation. Our two sibs exhibit several of these features (table). The behavioural problems in one child would support the suggestion by Mehta et $a l^{8}$ that behaviour disorder may be a primary feature associated with partial deficiency $10 \mathrm{q}$.

While our two affected sibs show, as one might expect, some of the features described in previously reported cases of partial deficiency $10 \mathrm{q}$, and a few features in common with previously reported cases of partial duplication $10 \mathrm{p}$, the umbilical hernia present in both sibs has not previously been documented in either chromosome imbalance.

The case reports illustrate the potentially high risk for a carrier of a large pericentric inversion of producing viable recombinant offspring and, in this sibship, the considerable degree of overlap of the clinical features seen in such recombinants.

We would like to thank $\operatorname{Dr} R \mathrm{~F}$ Mueller for his advice and involvement.

\section{References}

1 Yunis JJ. High resolution of human chromosomes. Science 1976;191:1268-70.

2 Yunis E, Torres de Caballero O. Duplication deficiency as the result of meiotic segregation of a maternal inv(10). Hum Genet 1981;57:71-4.
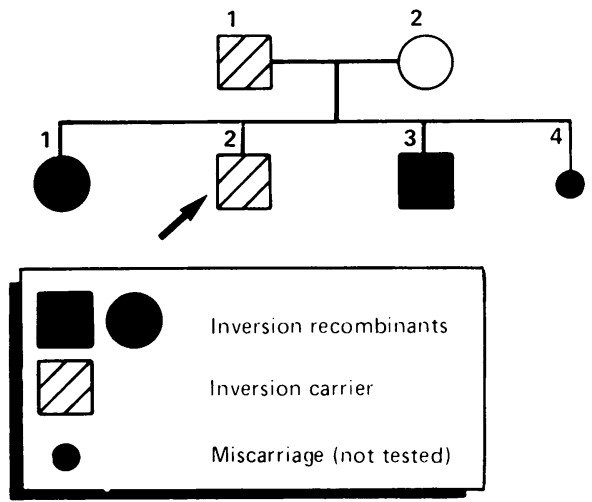

FIG 3 Family pedigree.

${ }^{3}$ Dutrillaux B, Laurent C, Robert JM, Lejeune J. Inversion pericentrique, inv(10), chez la mere et aneusomie de recombinaison, inv(10), rec(10), chez son fils. Cytogenet Cell Genet 1973;12:245-53.

4 Rodriguez MT, Martin MJ, Abrisqueta JA. Familial pericentric inversion(10) and its effect on two offspring. J Med Genet 1984;21:317-9.

5 Lansky-Shafer SC, Daniel WL, Ruiz L. Trisomy 10p produced by recombination involving maternal inversion(10)(p11q26). $J$ Med Genet 1981;18:59-75.

6 Lurie IW, Lazjuk GI, Gurevich DB, Kravtzova GI, Nedzved MK, Shved IA. Partial trisomy 10p in two generations. Hum Genet 1978;41:235-41.

7 Shapiro SD, Hansen KL, Pasztor LM, et al. Deletions of the long arm of chromosome 10. Am J Med Genet 1985;20:181-96.

${ }^{8}$ Mehta L, Duckett DP, Young ID. Behaviour disorder in monosomy 10qter. J Med Genet 1987;24:185-6.

Correspondence to Mr P Roberts, Regional Cytogenetics Unit, St James's University Hospital, Beckett Street, Leeds LS9 7TF. 